Corrigendum: Common variants at $12 q 15$ and 12q24 are associated with infant head circumference

H Rob Taal, Beate St Pourcain, Elisabeth Thiering, Shikta Das, Dennis O Mook-Kanamori, Nicole M Warrington, Marika Kaakinen, Eskil Kreiner-Møller, Jonathan P Bradfield, Rachel M Freathy, Frank Geller, Mònica Guxens, Diana L Cousminer, Marjan Kerkhof, Nicholas J Timpson, M Arfan Ikram, Lawrence J Beilin, Klaus Bønnelykke, Jessica L Buxton, Pimphen Charoen, Bo Lund Krogsgaard Chawes, Johan Eriksson, David M Evans, Albert Hofman, John P Kemp, Cecilia E Kim, Norman Klopp, Jari Lahti, Stephen J Lye, George McMahon, Frank D Mentch, Martina Müller-Nurasyid, Paul F O’Reilly, Inga Prokopenko, Fernando Rivadeneira, Eric A P Steegers, Jordi Sunyer, Carla Tiesler, Hanieh Yaghootkar, The Cohorts for Heart and Aging Research in Genetic Epidemiology (CHARGE) Consortium, Monique M B Breteler, Stéphanie Debette, Myriam Fornage, Vilmundur Gudnason, Lenore J Launer, Aad van der Lugt, Thomas H Mosley Jr, Sudha Seshadri, Albert V Smith, Meike W Vernooij, The Early Genetics \& Lifecourse Epidemiology (EAGLE) Consortium, Alexandra I F Blakemore, Rosetta M Chiavacci, Bjarke Feenstra, Julio Fernandez-Banet, Struan F A Grant, Anna-Liisa Hartikainen, Albert J van der Heijden, Carmen Iñiguez, Mark Lathrop, Wendy L McArdle, Anne Mølgaard, John P Newnham, Lyle J Palmer, Aarno Palotie, Annneli Pouta, Susan M Ring, Ulla Sovio, Marie Standl, Andre G Uitterlinden, H-Erich Wichmann, Nadja Hawwa Vissing, Charles DeCarli, Cornelia M van Duijn, Mark I McCarthy, Gerard H Koppelman, Xavier Estivill, Andrew T Hattersley, Mads Melbye, Hans Bisgaard, Craig E Pennell, Elisabeth Widen, Hakon Hakonarson, George Davey Smith, Joachim Heinrich, Marjo-Riitta Jarvelin \& Vincent W V Jaddoe for the Early Growth Genetics (EGG) Consortium Nat. Genet. 44, 532-538 (2012); published online 15 April 2012; corrected after print 8 May 2013

In the version of this article initially published, Thorkild I.A. Sørensen was listed incorrectly as a contributing member of the EGG Consortium. The error has been corrected for the HTML and PDF versions of this article.

\title{
Corrigendum: Germline mutations affecting the proofreading domains of POLE and POLD1 predispose to colorectal adenomas and carcinomas
}

Claire Palles, Jean-Baptiste Cazier, Kimberley M Howarth, Enric Domingo, Angela M Jones, Peter Broderick, Zoe Kemp, Sarah L Spain, Estrella Guarino Almeida, Israel Salguero, Amy Sherborne, Daniel Chubb, Luis G Carvajal-Carmona, Yusanne Ma, Kulvinder Kaur, Sara Dobbins, Ella Barclay, Maggie Gorman, Lynn Martin, Michal B Kovac, Sean Humphray, The CORGI Consortium, The WGS500 Consortium, Anneke Lucassen, Christopher C Holmes, David Bentley, Peter Donnelly, Jenny Taylor, Christos Petridis, Rebecca Roylance, Elinor J Sawyer, David J Kerr, Susan Clark, Jonathan Grimes, Stephen E Kearsey, Huw J W Thomas, Gilean McVean, Richard S Houlston \& Ian Tomlinson

Nat. Genet. 45, 136-144 (2013); published online 23 December 2012; corrected after print 8 May 2013

In the version of this article initially published, the name of author Estrella Guarino was incorrectly listed as Estrella Guarino Almeida. The error has been corrected in the HTML and PDF versions of this article.

\section{Corrigendum: Common variants at $6 q 22$ and $17 q 21$ are associated with intracranial volume}

M Arfan Ikram, Myriam Fornage, Albert V Smith, Sudha Seshadri, Reinhold Schmidt, Stéphanie Debette, Henri A Vrooman, Sigurdur Sigurdsson, Stefan Ropele, H Rob Taal, Dennis O Mook-Kanamori, Laura H Coker, W T Longstreth Jr, Wiro J Niessen, Anita L DeStefano, Alexa Beiser, Alex P Zijdenbos, Maksim Struchalin, Clifford R Jack Jr, Fernando Rivadeneira, Andre G Uitterlinden, David S Knopman, Anna-Liisa Hartikainen, Craig E Pennell, Elisabeth Thiering, Eric A P Steegers, Hakon Hakonarson, Joachim Heinrich, Lyle J Palmer, Marjo-Riitta Jarvelin, Mark I McCarthy, Struan F A Grant, Beate St Pourcain, Nicholas J Timpson, George Davey Smith, Ulla Sovio, the Early Growth Genetics (EGG) Consortium, Mike A Nalls, Rhoda Au, Albert Hofman, Haukur Gudnason, Aad van der Lugt, Tamara B Harris, William M Meeks, Meike W Vernooij, Mark A van Buchem, Diane Catellier, Vincent W V Jaddoe, Vilmundur Gudnason, B Gwen Windham, Philip A Wolf, Cornelia M van Duijn, Thomas H Mosley Jr, Helena Schmidt, Lenore J Launer, Monique M B Breteler \& Charles DeCarli for the Cohorts for Heart and Aging Research in Genomic Epidemiology (CHARGE) Consortium

Nat. Genet. 44, 539-544 (2012); published online 15 April 2012; corrected after print 27 April 2012; corrected after print 8 May 2013

In the version of this article initially published, Thorkild I.A. Sørensen was listed incorrectly as a contributing member of the EGG Consortium. The error has been corrected for the HTML and PDF versions of this article. 